\title{
AGE- AND SEX-DETERMINED DIFFERENCES IN THE ESTABLISHMENT OF TETANUS ANTITOXIN PRODUCTION IN GUINEA-PIGS
}

\author{
L. A. RÉTHY ${ }^{1 *}$, Magdolna GÉRESI ${ }^{2}$ and L. RÉTHY ${ }^{1+}$ \\ ${ }^{1}$ Independent Research Group for Immunology and Genetics, H-1111 Budapest, \\ Egry J. u. 19-21, Hungary; ${ }^{2}$ State Serum and Vaccine Institute 'Phylaxia', \\ Budapest, Hungary
}

(Received April 20, 2000; accepted October 30, 2000)

\begin{abstract}
For lack of relevant data of the literature, the tetanus immunisation results obtained in the two sexes were compared in an animal model. Complete immunisation series of weaned, adult and aged guinea-pigs (20-25 animals/group) were performed with aluminium phosphate $\left(\mathrm{AlPO}_{4}\right)$ adsorbed purified tetanus toxoid (PTAP) as well as with typhoid-tetanus vaccine (TY-TE) containing lipopolysaccharide (LPS). Both vaccines contained 5.0 Lf (limes flocculans, Ramon) per single dose of tetanus toxoid, purity degree: $1500 \mathrm{Lf} / \mathrm{mg}$ protein nitrogen $(\mathrm{PN})$. Tetanus antitoxin titres (TAT) were measured after the first shot, and subsequently before and after booster. Compared to TAT of male animals, significantly lower titres were found in female animals after basic immunisation with PTAP in all the three age groups: 1.03 vs. $0.57,8.75$ vs. 5.64 , and 0.27 vs. $0.15 \mathrm{IU}$ (international units, related to the Copenhagen International Standard) per ml (sex-chromosomedependent differences?), as well as in adult animals immunised with TY-TE, before booster: 0.07 vs. $0.02 \mathrm{IU} / \mathrm{ml}$ (hormone-dependent differences?). In the latter case the TAT results after booster were 14.49 vs. $12.89 \mathrm{IU} / \mathrm{ml}$. Thus, the lower female prebooster titres were counterbalanced by a quick and effective increase of titres following booster. These results are in accordance with our previous observations in humans (Réthy and Réthy, 1986). From our observations with tetanus immunisation series on guinea-pigs it can be concluded that TAT may be influenced by the effects of sex chromosomes as well as of sexual hormones. During active anti-tetanus immunisation with LPS-containing vaccine (TY-TE) the lower adult female prebooster titres are presumably counterbalanced by the better functionality of the female immune memory.
\end{abstract}

Key words: Age, sex, anti-tetanus immunity, LPS, immunomodulation, immune memory

\footnotetext{
*Present address and working place: BETHESDA Children's Hospital of the Reformed Church, H-1147 Budapest, Bethesda u. 3, Hungary

${ }^{+}$Corresponding author; E-mail: retlaj@yahoo.com; Fax: +36 (1) 466-4329
} 
RÉTHY et al.

The preliminary results of Adler, who dealt with the immunological a spects of ageing (Adler and Nagel, 1982), showed a certain sex-determined diffe rence in antitoxin production following active anti-tetanus immunisation (Adler, personal communication). His data suggested that human females were disa dvantaged when compared to the immune responses achieved in males. Bearing this concept in mind, the authors investigated the differences in the acquisition of active anti-tetanus immunity in both sexes during a serologically controlled i mmunisation field trial in 1185 humans (Réthy and Réthy, 1986). Since there had been no comparative animal data, we started investigations aimed at comparing the dynamics of tetanus antitoxin production in female and male guinea-pigs.

\section{Materials and methods}

\section{Vaccines}

(i) $\mathrm{AlPO}_{4}$-adsorbed tetanus toxoid (PTAP). (ii) Aluminium hydroxide $\left[\mathrm{Al}(\mathrm{OH})_{3}\right]$ adsorbed typhoid-tetanus (TY-TE) vaccine containing as $S$. typhi antigen Boivin-Rauss-type endotoxin (Rauss et al., 1956). Both vaccines contained 5.0 Lf/single dose of tetanus toxoid. Purity degree: $1500 \mathrm{Lf} / \mathrm{mg} \mathrm{PN}$.

\section{Immunisation of guinea-pigs}

Three main groups of weaned, adult and aged Copenhagen White guineapigs were formed: $30-35$ animals (random-bred strain selected by Inga Scheibel in Statens Seruminstitut, Copenhagen; b red: Csanády farm, Budapest) were orig inally grouped per each experimental item (considering the losses occurring during the more than half-year-long lasting immunisation, bleedings, intercurrent il 1nesses, etc. processes). Basic immunisation: single shot. Booster immunisation: 6 months after basic/primary immunisation. The experimental animals, including the dams of newborn guinea-pigs, were isolated so that they could come into contact with tetanus toxoid exclusively at the times specified in the experimental pr otocol.

\section{Blood sampling and tetanus antitoxin titration}

Blood samples were taken (i) 28 days following the first immunisation, (ii) on the day of the recall immunisation and (iii) 14 days following the booster dose. The tetanus antitoxin titres were determined individually in conventionally bred 18-g mice (LATI, Gödöllö) according to the standard method described in the International (WHO) Pharmacopoeia at L+/1000 level. Because of deaths (naturally always) occurring during an experimental period (see Section 2), only the surv ivors' data were used for computation, i.e. 20-25 guinea-pigs per group. 


\section{Biometric analysis}

Biometric analysis included determination of (i) the arithmetical average of individual titres and (ii) the 95 percent confidential limits. For homogeneity of results (iii) the skewness and (iv) kurtosis were determined. To define the si gnificant differences, (v) Student's method was applied. SPSS and the JANDEL computer program were used.

\section{Results}

Observations on weaned guinea-pigs $(<150 \mathrm{~g})$. In weaned guinea-pigs the following results were observed (Table 1). The sex-determined differences in immune response averages manifested themselves following both the basic and recall immunisations with PTAP ( $\mathrm{p} \%$ of differences: $0.01-0.02$ ). There were no such differences present among animals immunised with the TY-TE vaccine. The normal distribution of individual antitoxin titres in each group was co nfirmed by the values of kurtosis and skewness corresponding to $<2$ to $>-2$.

\section{Table 1}

Antitoxin titre averages of weaned guinea-pigs immunised with PTAP and/or typhoid-tetanus vaccine and ranked according to sex

\begin{tabular}{|c|c|c|c|c|c|c|}
\hline & \multicolumn{2}{|c|}{ Basic immunisation, IU/ml } & \multicolumn{2}{|c|}{$\mathrm{IU} / \mathrm{ml}$ before recall } & \multicolumn{2}{|c|}{$\mathrm{IU} / \mathrm{ml}$ after recall } \\
\hline & males & females & males & females & males & females \\
\hline PTAP & 21 & 21 & 21 & 19 & 21 & 21 \\
\hline average & 1.03 & 0.57 & 0.05 & 0.03 & 4.19 & 2.95 \\
\hline$[ \pm] 95 \%$ conf. limit & 0.76 & 0.44 & 0.02 & 0.03 & 1.48 & 0.83 \\
\hline TY-TE & 23 & 23 & 23 & 23 & 23 & 24 \\
\hline average & 2.27 & 2.43 & 0.08 & 0.09 & 5.47 & 5.88 \\
\hline$[ \pm] 95 \%$ conf. limit & 0.83 & 1.06 & 0.05 & 0.05 & 1.68 & 1.85 \\
\hline
\end{tabular}

Observations on adult guinea-pigs (300 $\mathrm{g}$ and $>300 \mathrm{~g}$ ). The data of the average titres are contained in Table 2. Sex-dependent differences in the immune responses in these groups were significant only after basic immunisation. Ho wever, this difference became tendency-like before booster and disappeared after booster ( $\mathrm{p} \%$ 0.001-0.002). Concerning the results of immunisation with TY-TE, slight differences in titres were present in all phases. The differences were si gnificant only before recall. Homogeneity is proven by the numerical data of ku rtosis and skewness equalling $<2$ to $>-2$. 
Table 2

Antitoxin titre averages of adult guinea-pigs immunised with PTAP and/or TY-TE vaccine and ranked according to sex

\begin{tabular}{|c|c|c|c|c|c|c|}
\hline & \multicolumn{2}{|c|}{ Basic immunisation, IU/ml } & \multicolumn{2}{|c|}{$\mathrm{IU} / \mathrm{ml}$ before recall } & \multicolumn{2}{|c|}{$\mathrm{IU} / \mathrm{ml}$ after recall } \\
\hline & males & females & males & females & males & females \\
\hline PTAP & 28 & 28 & 25 & 26 & 28 & 26 \\
\hline average & 8.75 & 5.64 & 0.11 & 0.07 & 8172 & 8.69 \\
\hline$[ \pm] 95 \%$ conf. limit & 2.34 & 1.96 & 0.05 & 0.05 & 1.73 & 1.47 \\
\hline TY-TE & 25 & 27 & 30 & 30 & 29 & 29 \\
\hline average & 11.3 & 7.14 & 0.07 & 0.02 & 14.49 & 12.89 \\
\hline$[ \pm] 95 \%$ conf. limit & 2.39 & 1.59 & 0.04 & 0.01 & 2.24 & 2.5 \\
\hline
\end{tabular}

Observations on aged animals (> 3 years of age) (see Table 3). Differences of the titres were present only after basic immunisation in these groups ( $\mathrm{p} \%$ 0.002). No differences were found in averages of individual immune responses $b$ efore and after PTAP recall, as well as following immunisations with TY-TE. Values of kurtosis and skewness were between $<2$ to $>-2$.

\section{Table 3}

Antitoxin titre averages of aged guinea-pigs immunised with PTAP and/or TY-TE vaccine and ranked according to sex

\begin{tabular}{|c|c|c|c|c|c|c|}
\hline & \multicolumn{2}{|c|}{ Basic immunisation, IU/ml } & \multicolumn{2}{|c|}{$\mathrm{IU} / \mathrm{ml}$ before recall } & \multicolumn{2}{|c|}{$\mathrm{IU} / \mathrm{ml}$ after recall } \\
\hline & males & females & males & females & males & females \\
\hline PTAP & 21 & 22 & 20 & 21 & 20 & 23 \\
\hline average & 0.27 & 0.15 & 0.05 & 0.05 & 1.85 & 1.7 \\
\hline$[ \pm]$ 95\% conf. limit & 0.23 & 0.13 & 0.04 & 0.05 & 0.47 & 0.88 \\
\hline TY-TE & 23 & 20 & 21 & 22 & 23 & 24 \\
\hline average & 2.42 & 2.9 & 0.09 & 0.09 & 4.08 & 4.16 \\
\hline$[ \pm] 95 \%$ conf. limit & 1.13 & 1.27 & 0.04 & 0.04 & 0.8 & 0.88 \\
\hline
\end{tabular}

\section{Discussion}

After basic immunisation with PTAP, the antitoxin titres of female an imals were significantly lower compared to the titres of males, in each invest $i$ gated age group. These significant, sex-dependent differences disappeared before and after booster immunisations with PTAP. 
TY-TE vaccination results showed another sex-dependent distribution: significantly lower tetanus antitoxin titres of adult female animals were present only before booster immunisation; this, however, was counterbalanced by the quick and effective increase of the titres after booster.

The results obtained with the PTAP immunisation of guinea-pigs, e.g. that sex-dependent differences detected after the first shot disappeared later, indicate that the functionality of the immune memory showed no sex-dependent difference in the investigated age groups. The functionality of the immune memory has been characterised by us by the degree of increase of titres following booster.

The sex-dependent differences detected after the first PTAP shot cannot be explained by the hormonal effects of adult life, as similar sex-dependent diffe rences could be observed in groups of weaned and aged animals as well. Rather, a non-hormonal effect of one or both of the sex chromosomes seems to be more likely in this case.

When applying LPS-containing vaccine (TY-TE), sex-dependent differences could be detected before booster, but only within the group of adult an imals. The lack of sex-dependent differences in weaned and aged animals imm unised with LPS-containing vaccine coincides with the absence of physiologically significant amounts/effects of sex hormones in these age groups. These observ ations suggest a role of hormonal effects in the maintenance of sex-dependent di fferences in the adult group of immunised animals.

The lower female prebooster titres observed in adult animals were cou nterbalanced by a quick and effective increase of titres following booster or, in other words, by the better functionality of the female immune memory, co mpared with the results achieved in male animals.

These observations are in accordance with our previous, only partly pu blished observations in humans (Réthy and Réthy, 1986). In humans, according to our previous observations, LPS can alter the dynamics of the male immune $\mathrm{r}$ esponse, with a shift to the female-like pattern: lower prebooster titres, with a quick and effective titre increase after booster. LPS is an effective immunomodulating agent (Réthy and Réthy, 1988). Dehydroepiandrosterone (DHEA) has emerged recently as a major immunoregulatory steroid hormone ( Berczi and Szentiványi, 1996; Berczi, 1998). Our observations suggest that female sexual hormones may also have a significant impact on immunomodulation. These o bservations are supported by findings of other investigators. Oestrogen stimulated enhancement of interleukin-1 (IL-1) beta promoter activity in a dose-dependent manner in certain tissues. Oestrogen can synergise LPS in this enhancement. (Ruh et al., 1998). Oestrogen receptor regulates nuclear factor kappa B and AP-1 activity in a cell-specific manner (Cerillo et al., 1998). Oestradiol and progeste rone inhibited the production of IL-1 from human peripheral monocytes. Under conditions with low levels of sexual hormones monocytes produce IL-1 more readily in response to stimulation by LPS (Morishita et al., 1999). The effect of 
LPS on male and female immune responses, observed in our experiments, may be explained by similar effects.

Conclusions: The sex-dependent differences observed in TA titres fo 1lowing PTAP immunisation of guinea-pigs regardless of their age suggest that sex chromosomes may exert an influence on the immune response. Following LPS-containing TY-TE vaccination, the lower adult female prebooster titres were counterbalanced by the better functionality of the female immune memory. This phenomenon, observed exclusively in the groups of adult animals, may be dependent on the presence of se xual hormones.

\section{Acknowledgements}

We gratefully acknowledge the helpful discussions with Professor M. Kellermayer (Institute for Clinical Chemistry, University of Pécs) and the support received from both the late Dr. J. Molnár, Director of State Serum and Vaccine Institute 'Phylaxia' and the Hungarian Ministry of Health with grant no. ETT 05-054/99.

\section{References}

Adler, W. H. and Nagel, J. E. (1982): Immunological Aspects of Aging. Marcel Dekker, Inc., New York and Basel.

Berczi, I. (1998): Neurohormonal host defense in endotoxin shock. Ann. N. Y. Acad. Sci. 840, 787-802.

Berczi, I. and Szentiványi, A. (1996): The pituitary gland, psychoneurology and infection. In: Fredman, H., Klein, T. and Friedman, A. L. (eds) Psychoneurology, Stress and Infectious Disease. CRC Press, Boca Raton, FL. pp. 79-109.

Cerillo, G., Rees, A., Manchanda, N., Reilly, C., Brogan, I., White, A. and Needham, M. (1998): The oestrogen receptor regulates NFkappaB and AP-1 activity in a cell-specific manner. J. Steroid Biochem. Mol. Biol. 67, 79-88.

Morishita, M., Miyagi, M. and Iwamoto, Y. (1999): Effects of sex hormones on production of interleukin-1 by human peripheral monocytes. J. Periodontol. 70, 757-760.

Rauss, K., Kétyi, I. and Réthy, L. (1956): Preparation, control, results and perspectives of the adsorbed typhoid vaccine. Atti $2^{\circ}$. Congr. Internazz. di Standard. Microbiol., Institut Mérieux, Lyon. pp. 376-379.

Réthy, L. A. and Réthy, L. (1986): The age-and sex-dependent features of development of human immune memory. Ann. Immunol. hung. 26, 551-563.

Réthy, L. and Réthy, L. A. (1988): LPS-induced immunomodulation in man. In: Bizzini, B. and Bonmassar, B. (eds) Advances in Immunomodulation. Pythagora Press, Rome-Milan, pp. 381-388.

Ruh, M. F., Bi, Y., D’Alonzo, R. and Bellone, C. J. (1998): Effect of estrogens on IL-1 beta promoter activity. J. Steroid Biochem. Mol. Biol. 66, 203-210. 